\title{
Profile of Disability in Selected Districts in Rwanda
}

\author{
Urimubenshi G., Sagahutu J.B. , Kumurenzi A., Nuhu A., Tumusiime D., Kagwiza J. \\ Department of Physiotherapy, College of Medicine and Health Sciences, University of Rwanda \\ Correspondence \\ Gerard Urimubenshi, Department of Physiotherapy, School of Health Sciences, College of Medicine and Health \\ Sciences, University of Rwanda, P.O. Box 3286 Kigali, Rwanda・E-mail: ugerard@khi.ac.rw
}

\begin{abstract}
SUMMARY
Disability prevalence data are important to improve efforts to remove or minimize disabling barriers and provide services to allow people with disabilities to take part in community life. There is however a lack of reliable data on disability in the districts of Rwanda.

This study aims to describe the profile of disability in terms of prevalence, age, gender distribution as well as activity limitation in Rwanda.

A door-to-door survey was conducted in all the households in villages from three districts selected through a multi-stage sampling procedure. Identified persons were assessed for activity limitations using instruments developed from domains in the International Classification of Functioning, Disability and Health (ICF). Data were analysed descriptively and presented by district, age, gender, and activity limitation.

Disability prevalence rates of $10.1 \%$ (Ruhango), 9.1\% (Kayonza), and 6.0\% (Nyagatare) were obtained. An overall average prevalence of disability in the three districts was $8.3 \%$. The prevalence of disability was higher in adults than in children in all the three districts with Ruhango having $13.6 \%$ vs $7.0 \%$; Kayonza, $12.4 \%$ vs $6.4 \%$; and Nyagatare, $8.9 \%$ vs $2.8 \%$. The main activity limitations experienced by children with disability were sitting, seeing, and crawling, while adults with disabilities had difficulties mainly in seeing and walking.

Persons identified with disability in this study from three districts in Rwanda have various activity limitations. The findings provide a useful resource for planning rehabilitation services and to direct future enquiry into the epidemiology of disability in other districts of Rwanda.
\end{abstract}

KEY WORDS: disability, prevalence, ICF, Rwanda

\section{INTRODUCTION}

Disability is a global problem affecting both developed and developing countries. Worldwide, people with disability are estimated to be more than one billion, and nearly 200 million of them experience considerable difficulties in functioning (World Health Organization (WHO), 2011).

In 2006, the United Nations (UN) adopted the International Convention on the Rights of People With Disabilities (PWDs). Now, many governments and international development agencies are turning their attention to the goal of including PWDs in development (Mont, 2007).
Although disability is a public issue, the resources to manage it are not equitably allocated (Kelemen et al., 2013). Among developing countries, it is estimated that only $2 \%$ of people with disability receive any rehabilitation whatsoever (Department for International Development (DFID), 2004). In Africa, there are only 6 physician specialists in physical and rehabilitation medicine, whereas regions such as China have up to 10,000 specialists (Haig et al., 2009). The reasons for the mis-allocation of resources are many and complex. However one probable reason is difficulty in obtaining information on the extent and cost of disability in low-resource regions (Kelemen et al., 2013). 
The World Report on Disability emphasizes the importance of disability prevalence data to "improve efforts to remove disabling barriers and provide services to allow people with disabilities to participate" (WHO, 2011) in community life. Recommendation 8 of this report is "Improve Data Collection" [p.267], a clear indication of lack of data and the priority nature of research. Similarly, the United Nations Children's Fund (UNICEF) State of the World's Children Report emphasizes the importance and complexity of data collection related to disability (UNICEF, 2011).

Despite the magnitude of the issue, both awareness of and scientific information on disability are lacking. Various publications show disability figures, but these figures vary significantly in both developed and developing countries. This variation can be attributed to several factors including differing definitions of disability, different methods of data collection, and variation in the quality of design of studies investigating disability (Mont, 2007).

Rwanda is one such country in which disability prevalence varies significantly. The 2002 census conducted in Rwanda, which used household questionnaires, revealed that the prevalence of disability was $3.9 \%$ (National Institute of Statistics of Rwanda (NISR), 2005). The recent census conducted in 2012 showed a prevalence of disability $5 \%$ (NISR, 2012).

However, given Rwanda's history of genocide against the Tutsi in 1994 and the poor economy, a more realistic prevalence of disability may be closer to the worldwide estimation of $15 \%$ (WHO, 2011). Underestimating the number of PWDs is likely, due to the stigma attached to disability in the Rwandan society, where some households may not declare members as having a disability (Thomas, 2005). In addition, the assessment procedures may be another reason for the underestimated prevalence of disability in Rwanda.

In response to the unavailability of reliable data about disability in Rwanda, a door-to-door survey was conducted using an instrument based on the International Classification of Functioning, Disability, and Health (ICF). The framework yielded a disability prevalence of $11.5 \%$ (M'kumbuzi et al., 2014). However, as pointed out previously, the study by M'kumbuzi et al. (2014) was carried out in only two districts - Musanze and Bugesera and the results cannot be generalized for all the districts.

On another hand, it is most likely that there has been internal migration from districts such as Musanze with high population density of $695 / \mathrm{sq} \mathrm{km}$ to those with low density such as Kayonza and Nyagatare with 179 and 243 per sq $\mathrm{km}$ respectively (NISR, 2012). People with disability are not likely to migrate at the same rate as people without disability, and hence there may be lower disability prevalence in the newly-populated regions. There are two other shortcomings in the previous study by M'kumbuzi et al. (2014). First, although "hearing" limitation was found to be significant among PWDs in various countries (Njelesani et al., 2011), it was not assessed while screening activity limitations among adults with disabilities. Secondly, fits and strange behaviour were not distinguished in one of the two districts. This might have resulted in underestimating the prevalence of disability.

This study is aimed at addressing such limitations to establish the profile of disability in three different districts of Rwanda. It is envisaged that this paper will provide public, private, national, local and international organizations, and the organizations of PWDs with baseline data to improve efforts to prevent disability, and plan services allowing PWDs to take part in community life. The findings may provide insight for other low-income countries like Rwanda.

\section{METHODS}

\section{Study Setting, Population and Sampling}

This study was the second phase of the programme by the Department of Physiotherapy of the University of Rwanda to establish the country's profile of disability, being conducted in one district each year. The districts of Musanze in the northern province and Bugesera in the eastern province of Rwanda were covered during the first phase of the programme as described by M'kumbuzi et al. (2014).

This second phase of the programme was conducted in Kayonza and Nyagatare districts in the eastern province, and Ruhango district in the southern province of Rwanda. A multi-stage sampling method was employed. Baseline surveys were conducted as a preliminary step to implementing community-based rehabilitation (CBR). Thus, purposive sampling of the eastern and southern provinces was done. Subsequently, further purposive sampling was employed to select two districts in the eastern province, and one district in the southern province. Kayonza district was selected through the initiative of Handicap InternationalRwanda in order to support its current project in 
conjunction with the Ministry of Local Government (MINALOC). The Nyagatare programme was initiated by nuns from Matimba through the AGAHOZO Association. The last district in this phase, Ruhango District, was selected because of the willingness expressed by Gatagara Rehabilitation Centre to meet the needs of PWDs through an organized programme. In each programme, the district hospitals were expected to sustain the CBR programme by providing technical support and willingly integrating PWDs into their developmental activities. The process of sample selection was described in a paper published earlier by M'kumbuzi et al. (2014).

Rwanda is among the most densely populated countries in Africa, with a density of 416 per sq $\mathrm{km}$ and a population of 10, 537, 222 in 2012 (NISR, 2012). Agriculture constitutes the main economic activity, though there is an increase in tourism. All the three selected districts are mostly rural, flat, dry, and warm. Over $90 \%$ of the population in these districts are engaged in agriculture. Around $65 \%$ of the families live below the poverty datum line.

\section{INSTRUMENTATION}

As described by M'kumbuzi et al. (2014), the same instruments were used to collect the data. Among the four instruments, the adult (18 years and above) and child (less than 18 years) disability screening tools were modified before being used. The functional activity of "hearing" was added in the screening form for adults with disabilities, while "fits" and "strange behaviour" for the screening of children with disabilities were distinguished.

All instruments were translated into Kinyarwanda, using a consensus methodology in a workshop involving community health workers, village leaders, participating rehabilitation professionals involved in the CBR fieldwork, and the researchers. Six group field trials (two in each district) were undertaken to test the validity and applicability of all the instruments.

\section{Data Collection Procedure}

Ethical clearance was obtained from the Kigali Health Institute (currently the College of Medicine and Health Sciences) Institutional Review Board in 2010. Permission for entry into each district was obtained from the mayor of the respective district and from the sector leaders as is the practice in Rwanda. Community consent for the door-todoor survey was obtained at a community meeting prior to the survey. Data were collected between 21 and 25 May 2012 in Kayonza, 29 April and 3 May 2013 in Nyagatare, 5 and 9 May 2014 in Ruhango District.

After obtaining permission from local authorities and consent from the population, the community was engaged in a 'social mobilization and awareness raising campaign'. This included discussions, demonstrations, and drama illustrating and defining disability, its causes, the different types, rehabilitation services as well as the role of the community and organizations representing PWDs in meeting the needs of PWDs. Various technical experts in physiotherapy, orthopaedic technology, ophthalmology, mental health, education, nursing, and social welfare addressed the community at a meeting held for all members of the community at each study site. Questions and answers time was also accommodated. The purpose of this social mobilization was to ensure that the community members understood disability in the first instance. Secondly, that they appreciated the importance of their participation in the door-to-door survey by demystifying and de-stigmatizing disability as well as sharing the alternatives available for rehabilitation for different categories of disability. Thus social mobilization was intended to empower the communities but also to limit potential barriers to accessing PWDs during the survey at both the household and community levels.

The second stage included training community health workers (CHWs) and participating technical experts as research assistants. The former were pre-selected by the community. All research assistants reviewed the instruments used, and were trained to identify, screen, and refer PWDs during the survey and as an ongoing activity.

Disability is defined as "the negative aspects of the interaction between an individual (with a health condition) and that individual's contextual factors (personal and environmental factors)". Interactions include impairments (affecting the body), activity limitations (affecting actions), and participation restrictions (affecting experience of life) (WHO, 2001). In this study, disability or being disabled was operationalized as having at least a difficulty or being unable to perform on any key or core activity of daily living (Braithwaite and Mont, 2009).

Research assistants were grouped. At least one CHW and one physiotherapist constituted a group. Two 
physiotherapy students were attached to a group for training purposes. Each group was allocated transects of the village to conduct the door-to-door survey to identify PWDs using the screening schedule. Identified persons were invited to a pre-arranged central outreach point to undergo a comprehensive rehabilitation assessment by professionals on the next day. A mobile clinic also conducted home visits where PWDs had indicated they would be unable to visit the outreach point.

Specialized clinics were set up at the outreach point: mobility, ophthalmology, mental health, medical, education, and social welfare. Upon arrival, clients were registered at a reception station for each village and their screening form from the previous day retrieved. The screening form laid the basis for the clinic the client was sent to e.g. a client identified as having a 'seeing' difficulty was sent to the ophthalmology clinic. A rehabilitation team led by the technical expert in that field was stationed at each clinic. The client underwent a comprehensive examination and received appropriate services including referral to a facility for ongoing rehabilitation services. All assessment forms for PWDs were handed over to the district rehabilitation department to enable client follow-up.

\section{Analysis}

Data and assessment forms from the screening and from the comprehensive physical examination were entered into Microsoft Excel programme. The number of participants and the prevalence of disability were presented by district, age (adults and children), and gender. Descriptive statistics were computed to characterize the demographics of PWDs distributed by age group, gender, and district. Proportions were computed to summarize activity limitations and disaggregated by age ( 18 years and above = adult; less than 18 years $=$ child $)$.

\section{RESULTS}

Table 1 illustrates the population of the study settings and the proportion of the population with a disability distributed by age group. A total of 4,562 subjects were screened in this study from the three districts. Of the study population, $2,375(52.1 \%)$ were children and 2,187 (47.9\%) were adults. The study findings indicate that the total number of persons with disabilities was 377 making an average of $8.3 \%$. The results indicate that the prevalence of disability is higher in adults $(11.4 \%)$ than in children $(5.4 \%)$.
Out of the 377 persons with disabilities found in the three districts, $217(57.6 \%)$ were female and $160(42.4 \%)$ were male. The trend of a high proportion of females compared to males was observed in the Kayonza (female $64.3 \%$ vs male $35.7 \%$ ) and Nyagatare (female $54.8 \%$ vs male $45.2 \%$ ) districts whereas in Ruhango district, the proportion of males was slightly higher than females (male $52.5 \%$ vs female $47.5 \%$ ). Two-thirds of the persons with disabilities were adults $(249,66 \%)$ while the rest were children $(128,34.0 \%)$. The details of the distribution of PWDs by adulthood/childhood, district and gender are shown in table 2 .

Table 1. Population and disability prevalence by district and age group

\begin{tabular}{lcccccc}
\hline \multirow{2}{*}{ District } & \multicolumn{3}{c}{$\begin{array}{c}\text { Population, } \\
\text { frequency (\%) }\end{array}$} & \multicolumn{3}{c}{$\begin{array}{c}\text { Person with disability, } \\
\text { frequency (\%) }\end{array}$} \\
\cline { 2 - 7 } Kayonza & 1118 & 917 & 2035 & 71 & 114 & 185 \\
& $(54.9)$ & $(45.1)$ & $(100)$ & $(6.4)$ & $(12.4)$ & $(9.1)$ \\
Nyagatare & 743 & 807 & 1550 & 21 & 72 & 93 \\
& $(47.9)$ & $(52.1)$ & $(100)$ & $(2.8)$ & $(8.9)$ & $(6.0)$ \\
Ruhango & 514 & 463 & 977 & 36 & 63 & 99 \\
& $(52.6)$ & $(47.3)$ & $(100)$ & $(7.0)$ & $(13.6)$ & $(10.1)$ \\
\hline Total & 2375 & 2187 & 4562 & 128 & 249 & 377 \\
& $(52.1)$ & $(47.9)$ & $(100)$ & $(5.4)$ & $(11.4)$ & $(8.3)$ \\
\hline
\end{tabular}

Table 2. Distribution of persons with disability (PWDs) by district, gender and age group

\begin{tabular}{lcccc}
\hline District & Gender & $\begin{array}{c}\text { Children } \\
\mathrm{n}(\%)\end{array}$ & $\begin{array}{c}\text { Adults } \\
\mathrm{n}(\%)\end{array}$ & $\begin{array}{c}\text { Total } \\
\mathrm{n}(\%)\end{array}$ \\
\hline Kayonza & Female & $46(64.8)$ & $73(64.0)$ & $119(64.3)$ \\
& Male & $25(35.2)$ & $41(36.0)$ & $66(35.7)$ \\
Nyagatare & Female & $10(47.6)$ & $41(56.9)$ & $51(54.8)$ \\
& Male & $11(52.4)$ & $31(43.1)$ & $42(45.2)$ \\
Ruhango & Female & $12(33.3)$ & $35(55.6)$ & $47(47.5)$ \\
& Male & $24(66.7)$ & $28(44.4)$ & $52(52.5)$ \\
\hline TOTAL & & $128(34.0)$ & $249(66.0)$ & $377(100)$ \\
\hline
\end{tabular}

Table 3 indicates the types of disability among PWDs who were identified and came back the following day for further assessment. A PWD could present with more than one type of disability, therefore the table illustrates the frequency of type of disability among the PWDs. Physical, mental, and visual disabilities were the most prevalent types of disability among children with almost the same 
percentage $(8.5,8.2$, and 8.0 respectively). In adults, physical disability was the most prevalent type of disability (24.4\%) followed by vision $(23.3 \%)$ and mental $(6.9 \%)$ disability. Hearing disability was the least prevalent type of disability in both adults and children.

Table 4 shows the distribution of activity limitations in children with disabilities (CWDs) in the three districts. Each child identified as having a disability could present with more than one activity limitation, therefore the table illustrates the frequency of each activity limitation in the CWDs. The results indicate that the most frequent activity limitations found in children with disabilities are sitting (64, $13.5 \%)$ followed by seeing $(63,13.3 \%)$, crawling (61, $12.8 \%)$, and walking $(60,12.6 \%)$ while the least was feeding-sucking $(16,3.4 \%)$.

Table 3. Frequency and percentage of the type of disability among PWDs by district

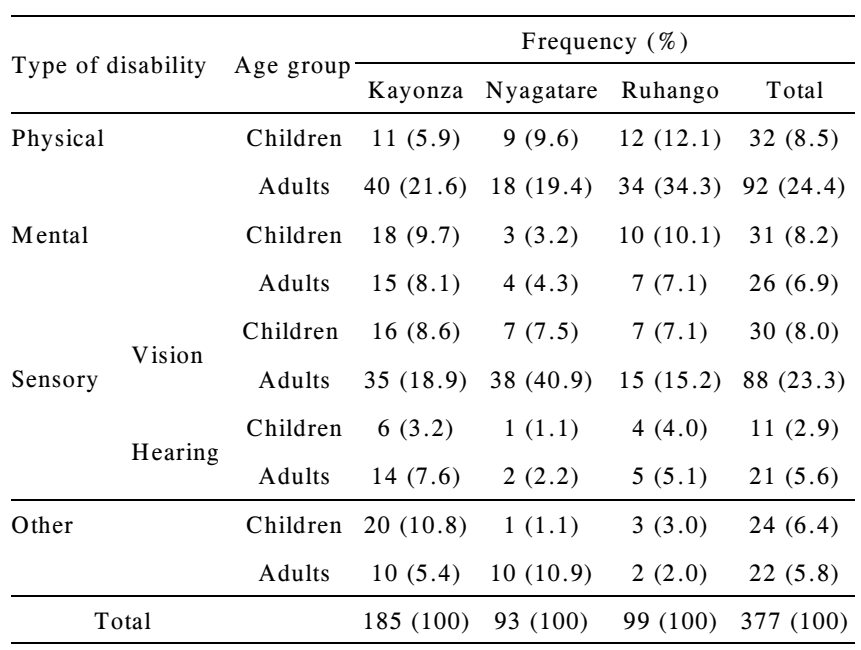

Table 4. Frequency of activity limitations among children with disabilities (CWDs) by district

\begin{tabular}{lcccc}
\hline \multirow{2}{*}{ Activity limitation } & \multicolumn{4}{c}{ Frequency $(\%)$} \\
\cline { 2 - 5 } & Kayonza & Nyagatare & Ruhango & Total \\
\hline Feeding-sucking & $7(2.7)$ & $2(4.6)$ & $7(4.1)$ & $16(3.4)$ \\
Hearing & $20(7.7)$ & $8(17.4)$ & $24(14.1)$ & $52(10.9)$ \\
Seeing & $36(13.9)$ & $5(10.9)$ & $22(12.9)$ & $63(13.3)$ \\
Sitting & $37(14.3)$ & $3(6.5)$ & $24(14.1)$ & $64(13.5)$ \\
Crawling & $35(13.5)$ & $2(4.6)$ & $24(14.1)$ & $61(12.8)$ \\
Walking & $32(12.4)$ & $5(10.9)$ & $23(13.5)$ & $60(12.6)$ \\
Talking & $32(12.4)$ & $2(4.6)$ & $21(12.4)$ & $55(11.6)$ \\
Fits & $17(6.6)$ & $3(6.5)$ & $6(3.5)$ & $26(5.5)$ \\
Strange behaviour & $18(6.9)$ & $3(6.5)$ & $8(4.7)$ & $29(6.1)$ \\
Learning & $25(9.7)$ & $13(28.3)$ & $11(6.4)$ & $49(10.3)$ \\
\hline Total & $259(100)$ & $46(100)$ & $170(100)$ & $475(100)$ \\
\hline
\end{tabular}

Table 5 illustrates the frequency of activity limitations in adults with disabilities (AWDs) in the three districts. Likewise, AWDs could present with more than one activity limitation. The results of this study indicate that seeing and walking were the most common activity limitations found in adults with disabilities in the three districts $33.8 \%$ and $18.4 \%$ respectively). Toilet use, strange behaviour, and hearing were also common activity limitations in adults with disabilities.

Table 5. Frequency of activity limitations in adults with disabilities (AWDs) by district

\begin{tabular}{lcccc}
\hline Activity & \multicolumn{4}{c}{ Frequency $(\%)$} \\
\cline { 2 - 5 } limitation & Kayonza & Nyagatare & Ruhango & Total \\
\hline Feeding & $0(0)$ & $1(0.9)$ & $0(0)$ & $1(0.4)$ \\
Sitting & $5(4.8)$ & $2(1.9)$ & $5(9.6)$ & $12(4.5)$ \\
Talking & $1(0.9)$ & $1(0.9)$ & $1(1.9)$ & $3(1.1)$ \\
Washing & $6(5.7)$ & $5(4.9)$ & $1(1.9)$ & $12(4.5)$ \\
Walking & $19(18.1)$ & $16(14.8)$ & $14(26.9)$ & $49(18.4)$ \\
Seeing & $30(28.6)$ & $44(40.7)$ & $16(30.7)$ & $90(33.8)$ \\
Getting dressed & $2(1.9)$ & $4(3.7)$ & $1(1.9)$ & $7(2.6)$ \\
Toilet use & $14(13.3)$ & $14(12.9)$ & $2(3.8)$ & $30(11.3)$ \\
Strange behaviour & $14(13.3)$ & $11(10.2)$ & $6(11.5)$ & $31(11.7)$ \\
Hearing & $14(13.3)$ & $10(9.3)$ & $7(13.5)$ & $31(11.7)$ \\
\hline Total & $105(100)$ & $108(100)$ & $53(100)$ & $266(100)$ \\
\hline
\end{tabular}

\section{DISCUSSION}

The door-to-door survey indicated that the average prevalence of disability was higher $(8.3 \%)$ than the $5 \%$ reported in the 2012 national census (NISR, 2012). The lower prevalence of PWDs found by the NISR (2012) is probably due to the stigma attached to disability in the Rwandan society where some households may not declare members as having a disability (Thomas, 2005), compared to the current study where there was social awareness mobilization about disability before data collection. This might have reduced the risk of not declaring some PWDs. A disability prevalence rate of $8 \%$ was reported in Tanzania (Njelesani et al., 2011), similar to the rate in the three districts. In northern Ethiopia, the rate was almost half as low rates, i.e. $4.9 \%$ (Tamrat, 2001). This low prevalence could be explained by the absence of the categories of questions related to feeding, sitting, washing, getting dressed, and using the toilet, in the Ethiopian survey, but which were included in this study. 
Overall, the findings from all the districts are lower than the WHO estimate of $15 \%$ (WHO, 2011). If the level of participation and contextual factors were considered in addition to the activity limitations in the present study, an even higher prevalence of disability may have been obtained (M'kumbuzi et al., 2014), though these findings provide sufficient and strong evidence of the need for rehabilitation services in the country.

Prevalence rates of $10.1 \%$ (Ruhango), 9.1\% (Kayonza), and $6.0 \%$ (Nyagatare) were found in the districts. The lower prevalence found in Nyagatare could be due to the rapid migration of persons without disabilities taking place in the district (NISR, 2012); only those who do not have a disability would migrate from a highly to a less populated district like Nyagatare.

However, further research is needed to provide evidence as to why Nyagatare recorded a lower prevalence rate compared with other districts. The difference in disability prevalence between the three districts highlights the fact that randomly sampling districts from a country like Rwanda may not generate data that can be reliably generalized for the country as a whole. The truer picture that emerges from surveying individual districts indicates that the extra time and effort required for research on all districts would not be a waste, as the findings can more accurately inform policy and service development. Rather than a limitation, purposive sampling in the case of disability prevalence studies may give data that is better able to inform prioritization of the development of services where resources are few.

The prevalence of disability for the three districts in general was found to be higher in adults than children. This is consistent with the results from the 2012 National Census (NISR, 2012). The result is also congruent with the findings from a similar study conducted in South Africa where the prevalence of disability was revealed to be $2.1 \%$ for persons aged zero to nine years. This percentage increased to $4.9 \%$ among persons aged 30 to 39 years, and further to $27.2 \%$ for those aged more than 80 years (Statistics South Africa, 2001). These findings suggest that while rehabilitation services for children are essential, rehabilitation service as part of comprehensive health care for adults and senior citizens is important.

Physical and visual disabilities were the most prevalent types of disability. This is supported by the results from a similar study conducted in north western Ethiopia by Fitaw et al. (2006) which revealed that disability in the lower locomotor was the most frequently reported type $(442=$ $47.0 \%)$ followed by blindness $(269=28.6 \%)$, upper motor $(152=16.1 \%)$, mental retardation $(97=10.3 \%)$, and hearing loss $(78=8.3 \%)$.

Limitation in vision has been reported as the leading type of disability in several countries in sub-Saharan Africa such as South Africa (Statistics South Africa, 2001) and Zambia (Eide and Loeb, 2006). The United States Agency for International Development (USAID) (2009) reported that the prevalence of visual disability in Europe and Eurasia is $2.5 \%$. High levels of visual limitation are associated with the need for mobility training (National Council for the Blind of Ireland, 2008), including provision of the appropriate mobility aids. Physical disability being the most prevalent may be attributed to the 1994 genocide committed in Rwanda where many people died and others survived with multiple physical trauma (Thomas, 2005).

The current study provides useful information on the profile of disability in Rwanda. The survey is however limited to three districts and the findings may not be generalized for the whole country. In addition, the causes and severity of disability were not assessed in this study. Furthermore, the study did not identify the participation restrictions. There was also lack of distinction between capacity and performance of the activity. Nevertheless, the paper provides a resource tool to assist anyone interested in disability issues by presenting a picture of disability in three districts in Rwanda.

\section{CONCLUSION}

The prevalence of disability was found to be higher than what was reported in the 2012 National Census in Rwanda, and it was higher in adults than in children. Planning new rehabilitation services and strengthening the existing ones for PWDs in Rwanda is suggested.

An education or awareness programme on the types and causes of disability, and the need and benefit of rehabilitation, is also essential as this could help PWDs to take full advantage of rehabilitation services. Further survey in other districts of Rwanda is also recommended.

\section{Acknowledgements}

The authors thank the participants in this study and acknowledge the contribution of the 4th year Physiotherapy 
Honours classes of 2012, 2013, and 2014 from Kigali Health Institute (currently the College of Medicine and Health Sciences), the rehabilitation team from Gahini District Hospital, Handicap International-Rwanda, Rilima, Matimba, and Gatagara/Nyanza Rehabilitation Centres for data collection and collation.

\section{References}

Braithwaite J. and Mont D. 2009. Disability and poverty: a survey of World Bank poverty assessments and implications. ALTEREuropean Journal of Disability Research/Revue Européenne de Recherche sur le Handicap 3(3): 219-232.

Fitaw Y. and Boersma J.M.F. 2006. Prevalence and impact of disability in north-western Ethiopia. Disability and Rehabilitation 28(15): 949-953.

DFID. 2004 Disability KAR: Assessing connections to DFID's poverty agenda. [Online] Available from: http://www.disabilitykar.net/pdfs/isabel_ortiz_report_final1. pdf. [Accessed: 21 ${ }^{\text {st }}$ March 2015].

Eide A.H. and Loeb M. 2006. Living Conditions among People with Activity Limitations in Zambia: A National Representative Study. [Online] Available from: http://www.sintef.no/upload/Helse/Levek\%C3\%A5r\%20og \%20tjenester/ZambiaLCweb.pdf. [Accessed: 27 ${ }^{\text {th }}$ March 2015]

Haig A. J., Jonathan I.M., Adewole D., Nelson V. and Krabak B. 2009. The practice of physical medicine and rehabilitation in Africa and Antarctica: A white paper or a black mark. Simultaneous publication. Journal of Rehabilitation Medicine 41(6): 401-405

Kelemen B.W., Haig A.J., Goodnight S. and Nyante G. 2013. The nature and prevalence of disability in a Ghanaian community as measured by the Language Independent Functional Evaluation. The Pan African Medical Journal 14(1): 103. Available from: http://www.panafrican-med journal.com/content/article/14/103/full/. [Accessed: 27 $7^{\text {th }}$ March 2015]

M'kumbuzi V.R.P., Sagahutu J.B., Kagwiza J., Urimubenshi G., and Mostert-Wentzel K. 2014. The emerging pattern of disability in Rwanda. Disability and Rehabilitation 36(6): 472478.

Mont D. 2007 Measuring Disability Prevalence. [Online] Available from:

http://siteresources.worldbank.org/DISABILITY/Resources/ Data/MontPrevalence.pdf [Accessed: 10 ${ }^{\text {th }}$ October 2014]

National Council for the Blind of Ireland. 2008. National Mobility
Report: Mobility experiences and perceptions of blind and vision impaired persons. [Online] Available from: https://www.ncbi.ie/sites/default/files/exec_summary_web.p df. [Accessed: 17 $7^{\text {th }}$ January 2015].

National Institute of Statistics of Rwanda. 2005. Third Rwanda General Census of Population and Housing - 2002.

[Online] Available from:

http://www.statistics.gov.rw/publications/third-general-censuspopulation-and-housing-rwanda-final-results-statistical-tables. [Accessed: $7^{\text {th }}$ February 2015].

National Institute of Statistics of Rwanda. 2012. Counting the People of Rwanda. 2012 Population and Housing Census. [ $\mathrm{O}$ n l i n e ] A v a i l a b l e f $\mathrm{r}$ o m : http://statistics.gov.rw/publications/counting-people-rwanda2012-population-and-housing-census-phc. [Accessed: 2 $2^{\text {nd }}$ March 2015].

Njelesani A., Couto S. and Cameron D. 2011. Disability and rehabilitation in Tanzania: a review of the literature. Disability and Rehabilitation 33(23-24): 2196-2207.

Statistics South Africa. 2001. Prevalence of Disability in South Africa: Census 2001. [Online] Available from: www.statssa.gov.za. [Accessed: $8^{\text {th }}$ February 2015].

Tamrat G., Kebede Y., Alemu S., and Moore J. 2001. The prevalence and characteristics of physical and sensory disabilities in Northern Ethiopia. Disability and Rehabilitation 23(17): $799-804$.

Thomas P. 2005. Disability, Poverty and the Millennium Development Goals: Relevance, challenges and opportunities for DFID. [Online] Available from: http://digitalcommons.ilr.cornell.edu/gladnetcollect/256. [Accessed: $2^{\text {nd }}$ March 2015].

UNICEF. 2011. The State of the World's Children. [Online] Available from: http://www.unicef.org/sowc2011/. [Accessed: $7^{\text {th }}$ February 2015].

USAID. 2009. The Prevalence of Disability in Europe and Eurasia. Final Report. [Online] Available from: http://dec.usaid.gov. [Accessed: $7^{\text {th }}$ February 2015].

World Health Organization (WHO). 2001. International Classification of Functioning, Disability and Health (ICF). Geneva, Switzerland: WHO.

World Health Organization (WHO). 2011. World Report on Disability. [Online] Available from: http://whqlibdoc.who.int/publications/2011/978924085215_ eng.pdf.[Accessed: 24 ${ }^{\text {th }}$ January 2015]. 